\title{
La vida necesita ser pensada
}

\author{
Life needs to be thought
}

\section{Sergio Micco Aguayo}

${ }^{a}$ Abogado, Master en Ciencia Política y Doctor en Filosofía. Profesor del Instituto de Asuntos Públicos de la Universidad de Chile

Recibido el 17 de junio de 2017; aceptado el 25 de julio de 2017

Una vida sin examen no vale la pena ser vivida.

Sócrates

\section{Introducción}

Los tiempos de la medicina son los tiempos del mundo, es decir, llenos de oportunidades, pero también de alteración. Por ello, cada cierto tiempo nos hacemos el firme propósito de cambiar un poco nuestras vidas para que esta sea más lograda y plena, es decir, más feliz. Así, nos comprometemos a cuidar nuestro cuerpo, dedicarle un tiempo acrecentado a la familia y menos al trabajo, divertirnos más y presionarnos menos, etcétera. Sin embargo, al poco andar nos vuelve a gobernar la misma rutina de siempre, esa pequeña ruta que transitamos desde el hogar al trabajo y de ahí de vuelta al hogar, semanas y semanas, meses tras meses, año tras año. Por eso siempre es bueno hacer un alto en el camino y Pensar lo que hacemos, o, en otros términos, reflexionar acerca del sentido de la vida que estamos llevando.

\section{El pensar y el razonar}

A partir de Hannah Arendt, la verdad sea dicha, es que razonamos mucho y pensamos poco (Arendt 1984, pp.87112). Razonar es calcular cómo alcanzar un fin determinado, echando mano a los medios idóneos de que disponemos, dentro de determinadas circunstancias. Es lo que hace el equipo de salud al estudiar y deliberar acerca del diagnóstico médico y la terapia a seguir. Pensar, por otro lado, es dialogar con uno mismo en la búsqueda del sentido de las cosas. Es el meditar, tomando distancia del mundo, abriéndonos a él y sumergiéndonos en sus misterios. Esto es lo que no hacemos.

El pensar supone hacerse el tiempo para tener un silencioso y solitario diálogo con uno mismo; diálogo invisible e inmaterial, que no produce nada concreto. Cuando Auguste Rodin representó a un pensador lo hizo sentado y con la mano en la barbilla, como sosteniendo el centro de su humanidad: su cerebro, asentado en su cabeza. Cuando manifestamos que una persona está pensando es porque observamos su total y completa ausencia del aquí y del ahora, su semblante distraido, su vista ida, sus oídos sordos. Por eso decimos del pensador que vive en otro mundo.

El pensar demanda soledad, silencio y coraje, mucho coraje. El solo hecho que un colega se ponga a pensar, orientando la vista hacia el infinito produce risa -ii qué tipo más extraño!!-, preocupación -¿¿no estará deprimido-, o molestia -iiEs un ocioso!! Sócrates, el pensador por excelencia, fue denominado "tábano", pues aguijoneaba a sus conciudadanos para que reflexionaran acerca de sus vidas y para que no vivieran como perpetuamente dormidos. Sócrates fue definitivamente un ser molesto. No es raro que lo hayan condenado a muerte. Quien piensa se arriesga a darse cuenta que su vida no tiene el sentido que le atribuía. En consecuencia, nada más lejos de la verdad eso de que "el pensar no cuesta nada”. 
Pensar, esto es lo central, es buscar el sentido de las cosas ¿Pero qué queremos decir cuando nos preguntamos por el sentido? Cuándo Aristóteles se lo explicó a su hijo Nicómaco usó la imagen del arquero. El sentido es la orientación de la flecha que tensa el arco buscando dar en el blanco. Ese sentido es el que le da significado a las cosas. Declarar que se tiene un proyecto de vida es reconocernos como un proyectil lanzado al futuro, el más lejano, el de la hora postrera. Es en la antesala de la muerte en que, quizás, tendremos la oportunidad de realizar un balance de nuestras vidas. Ahí y sólo ahí sabremos el significado real, no el querido, de la vida que habitamos

¿Si quisimos y pudimos formar una familia morimos cargados de años y rodeados de hijos y nietos, comos los patriarcas del Antiguo Testamento? Es la pregunta del animal laborans, el de la labores del parto. ¿Estaremos satisfechos con los frutos de nuestro trabajo por cuatro décadas realizados? Es la inquietud del homo faber, del trabajador iHabremos actuado políticamemnte marchándonos de un mundo más justo del que nos vio nacer? Es la cuestión que interpela al homo civis, al ciudadano. ¿Habremos sido fieles a las creencias trascendentes que de jóvenes dijimos profesar? Es el ruego del homo religi su, del religioso. Estas son las preguntas que deben meditarse mediante el pensar, el de la búsqueda del sentido de la existencia.

Pensar, en consecuencia, no es cosa fácil; demanda soledad, silencio y coraje para descubrir el significado de las cosas, y el sentido o, acaso, el sin sentido, de la vida que estamos llevando. Por todo lo dicho tendemos a razonar mucho para alcanzar los objetivos que nos hemos puesto por delante, pero pensamos poco, muy poco.

\section{Alteración y vida inauténtica}

Hay otra forma de aproximarnos a la dificultad del pensar ya no desde los conceptos sino que de la existencia.

No pensamos porque vivimos alter-ados, es decir, nuestra existencia vive orientada hacia lo otro, no hacia uno mismo. José Ortega y Gasset escribe que si permitimos que las cosas en torno o las opiniones de los demás nos arrastren, dejamos de ser nosotros mismos, padeciendo alteración (Ortega y Gasset, 1953, p. 96). Martin Heidegger afirma que vivimos una vida inauténtica cuando nos dejamos sofocar por las habladurías y la avidez de novedades (Heidegger, 2015, pp. 169-172). Procuramos, no sin gran agobio, tener la casa, el auto y las vacaciones que los otros tienen. ¿Qué es lo que hacemos de nuestras vidas? Lo que el mundo sustilmente nos impone. Vivimos una vida anónima, indistinguible de la de los demás, vivimos en el reino del "se", donde gobierna totalmente el "se" dice o el "se" hace.
¿De dónde vienen este frenesí, esta vida alterada, esta existencia inauténtica?

Apunto a tres sospechosos de villanía: infames que viven en nuestra villa: trabajo, diversión y automatización.

\section{El trabajo como maldición}

Si los trabajos domésticos y profesionales no nos dan respiro es obvio que no tendremos tiempo ni ánimo para pensar en soledad y en silencio. Muchas veces el trabajo es una verdadera tortura. De hecho la etimología de la voz trabajo nos remite a la palabra latina tripalium, instrumento que los romanos usaban para esclavizar y los medievales para torturar. Nuestras ocupaciones laborales se transforman en una verdadera ocupación militar y de tanto ganarnos la vida, parece que la vamos perdiendo. Ciertamente que la profesión que ejercemos la elegimos más o menos autónomamente y nadie, a punta de latigazos, nos obliga a producir. En suma, somos libres y no esclavos. Sin embargo, no lo somos tanto si observamos lo que estamos haciendo del trabajo, cansancio y agobio, que quema nuestra alma agotada, experimentando un infarto espiritual; en el reflexionar de Byung-Chul Han

Este filósofo alemán de origen coreano nos describe la sociedad del cansancio en la existimos. Las enfermadades laborales más comunes serían "la depresión, el trastorno por déficit de atención con hiperactividad (TDAH), el trastorno límite de la personalidad (TLP) o el síndrome de desgaste ocupacional (SDO)" (Han, B.Ch., p. 331) ¿Por qué? Porque en nuestro afán de ser lo más productivo, competitivo y exitoso posibles nos sometemos a un verdadero régimen de auto explotación” (Han, B.Ch., p. 331). Peor aún si la racionalidad económica, la que todo lo invade, incluido vuestro arte del cuidar personas, les impone indicadores a cumplir y plazos a respetar. Asimismo surgen los ganadores y los perdedores: winners y loosers. Han escribe con tristeza "El lamento del individuo depresivo, "nada es posible, solamente puede manifestarse en una sociedad que cree que "todo es posible" (Han, B.Ch., 331).

¿En este estado de cosas, tendremos la quietud para pensar? No. Por el contrario la sociedad del rendimiento lleva a la del dopaje, el de los fármacos y de los estimulantes. Tras el trabajo no vendrá el pensar y, razonablemente, querremos divertirnos, echándonos a la cama. Hemos entrado en el mundo de la entretención como enajenación.

\section{La diversión como fuga}

Blaise Pascal, filósofo francés del siglo XVII, describió la alterada condición humana no a partir del trabajo sino que de la diversión. Pascal afirma que todas 
las desgracias del hombre proceden de una sola cosa: "no saber permanecer en reposo en una habitación" (fr., 136). ¿Por qué? Pues es aquí cuando el ser humano "siente entonces su nada, su abandono, su insuficiencia, su dependencia, su impotencia, su vacío" (fr, 131). Este será el momento del aburrimiento, la melancolía, la desesperación. Vida sin sentido cuyo final es la muerte, terminante y terminadora. Pascal lo dirá con fuerza. "El último acto es sangriento, por valiente que sea el resto de la obra; al final, echan un poco de tierra sobre la cabeza, y todo se ha terminado" (Bishop, p. 376). ¿Qué hacemos? Pues no darle mucha vuelta al asunto e intentar ser felices rehuyendo del dolor, de la enfermedad y de la muerte (fr., 133). ¿Cómo lo alcanzamos? Divirtiéndonos hasta el hartazgo.

La diversión, hoy por hoy, ha engendrado la alborotada y mediocre cultura que cultivamos: la sociedad del espectáculo al decir de Mario Vargas Llosa. La masificación de las sociedades lleva a la industria de la entretención en su máxima homogeneidad y vulgaridad. La publicidad y el consumismo penetran los intersticios más íntimos de nuestra existencia, incluida la amorosa. Las estrellas de televisión, cantantes y futbolistas reemplazan a los intelectuales y políticos de fuste de antaño. El uso de estupefacientes se extiende para atontar la conciencia y experimentar un ilimitado y autodestructivo placer. El arte de amar se banaliza y se incorpora a esta inagotable fábrica de insaciables deseo: la pornografía. Las religiones milenarias son reemplazadas por las sectas de altísima intimidad y atontada racionalidad. No creemos en Dios, pero sí en nigromantes y cartas astrales ¿Para qué seguir? De lo que se trata es de divertirse, no de pensar.

\section{La técnica como frenesí}

Vivimos en la automatización y en la hegemonía de la tecnología. Desde la invención de la palanca, la rueda y el ábaco nuestra vida se ha visto fortalecida. Faenas precisas, repetitivas y precisas son realizadas por maquinas. El computador hace tareas con una rapidez y precisión infinitamente superiores a quien lo usa, aunque no necesariamente mejores. Ustedes operan con alta tecnología y hoy mediante robots. La ciencia y tecnología nos gobierna generando una infinita complacencia por las máquinas y experimentando un marcado sesgo favorable a la automatización (Carr, pp. 83-105). Sin embargo, la tecnología está gobernada por la razón instrumental, no por el pensar. De lo que se trata es que nuestras acciones sean lo más eficaz, preciso, rápido y eficiente posibles. Todo lo contrario al pensamiento que estamos promoviendo, ese que busca sentido y no resultados, pensamiento meditativo.

La palabra griega que la denominaba era tekne que significaba saber hacer algo bien: técnico y ético: si se quiere era el saber hacer algo bueno bien. Ahora bien la técnica supone sistemas expertos y creciente especialización. Es su implacable lógica. Vemos que ese especialista sabe sanar el riñón y ese otro domina con absoluta pericia la curación del hígado. Pero quizás ambos, siendo técnicamente muy buenos, faltan al deber ético de no perpetuar una vida terminal de agudísimo dolor, para el paciente y sus familiares, incurriendo en lo que ustedes, entiendo, llaman "ensañamiento terapéutico". Técnicamente soberbios, éticamente calamitosos.

No hay soledad ninguna tampoco. El caso de la web esto es clarísimo. La mayoría de los norteamericanos, no importando su edad, se pasaba, el 2009, ocho horas y media al día mirando el televisor de su casa, normalmente de su habitación, el monitor de su computadora o la pantalla de su teléfono móvil. Con frecuencia se utilizan dos o incluso tres de estos dispositivos simultáneamente" (Carr, pp. 1110-111). En términos de relaciones interpersonales, lo sabemos bien "cuando estamos on line, a menudo nos mostramos ajenos a todo cuanto acontece en nuestro derredor". Nuestros adolescentes tienen un" tremendo interés por saber de las vidas de sus pares y una tremenda ansiedad ante la perspectiva de quedarse descolgados". Si dejan de enviar mensajes, corren el riesgo de volverse invisibles" (Carr, p. 146).

Ni tempo, ni soledad ni capacidad mental para meditar.

\section{Pensamientos finales}

Las cavilaciones anteriores no debieran ser entendidas como que estamos condenados a llevar una existencia sin sentido, al no poder meditar y discernir por culpa del trabajo, la diversión y la tecnología. Por el contrario, estos tres villanos de los que hemos hablado pueden trastocarse en nobles ciudadanos habitantes de la ciudadela del humanismo, dándole los más altos los significados a la condición humana.

\section{Homo faber}

Para Karl Marx el trabajo hace al ser humano por una milagrosa alquimia: lo subjetivo e interno, deviene objetivo y externo. Los conocimientos que estaban en la mente de cada uno de ustedes se concretan en la más precisa actuación del escalpelo. En su cometido ustedes, el equipo de salud, hacen cosas únicas e irrepetibles, pues nunca habrá cosa igual que "ese" parto y "ese" niño. En la labor de cada uno de ustedes se vive la alegría de ser reconocidos pues realizan una contribución que sólo ustedes pueden hacer. En cada rincón de la clínica, su lugar de trabajo, todo es sociabilidad, cooperación y solidaridad o no hay nada. En cierto 
modo en ese niño que nace o se cura el trabajo médico se inmortaliza, pues mientras esa creatura exista ustedes vivirán en ella, incluso después de muertos. Para el creyente mediante la labor se participa en la creación de la naturaleza y del mundo. ¿Por qué no pensar el trabajar?

\section{Homo habilis}

El ser humano tiene la increíble capacidad de desarrollar las más complejas tecnologías que amplían su poder y control sobre la naturaleza, el tiempo, el espacio, la sociedad. Lo que el cuerpo no puede hacer, la mente puede imaginar y crear. A través de la ciencia y la tecnología hacemos realidad mucho de nuestros sueños (Carr, 2015, p. 244-247). Hay tecnologías que aumentan nuestra fuerza física como un martillo; otras extienden los límites de nuestros sentidos como los anteojos que portamos; una tercera categoría nos permite, como la biogenética, remodelar la naturaleza como la biogenética y hay algunas de una cuarta clase que amplían nuestra capacidad mental (Carr, 2011, p. 62). Es mediante la tecnología que la humanidad edificó las pirámides del antiguo Egipto, construyó los acueductos romanos, levantó las catedrales medievales, descendió en la luna o en el abismo de los mares. La ciencia y tecnología nos puede dar tiempo para pensar. ¿Por qué no hacerlo?

\section{Homo ludens}

Miremos a esos niños, que estando gravemente enfermos, se ponen a jugar. Así se relajan, adquieren dominio de sí mismos, incluso se pueden estar preparando para la existencia adulta, si es que llegan a vivirla. Se hacen fuertes y ágiles mediante una ficción, ganando autoestima y personalidad, deviniendo en un eximio deportista. Ellos juegan libremente, pues si los obligan a jugar, no jugarán. La rutina del hospital se transforma en ocio, desinterés, superficialidad. Mientras juegan interrumpen la vida corriente en la clínica. En el mundo de la enfermedad aguda donde el futuro se hace incierto e impredecible, el juego aporta temporalmente un orden propio y absoluto, llevando al mundo imperfecto, a ratos aterrador, a una perfección provisional y limitada, el de las reglas insobornables del juego. Por todo lo anterior, sólo los seres humanos tienen la increíble capacidad de jugar, sabiendo que están jugando. La entretención es expresión de la grandeza humana, si lo pensamos un poco (Huizinga, pp. 13-29).

\section{Vida auténtica}

La nuestra puede ser una existencia auténtica, consecuente consigo misma, que se muestra ante los demás tal y como es. Quien es auténtico dice lo que piensa, hace lo que dice y decide lo que quiere hacer de su vida. ¿Cuáles son sus proyectos de vida? Los que se fundan en sus principios, se gobierna por sus creencias y se orienta en un sentido que han ustedes decidido. Principios, creencias y sentido que son verdaderamente suyos si los han pensado desde su raíz y han surgido en sus mentes y corazones promovidos por una incontrastable evidencia: esto es lo mio (Ortega y Gasset, 1953, p. 98). Para ello debemos detenernos, dialogar silenciosa y solitariamente con nosotros mismos descubriendo el sentido que le queremos dar a nuestra existencia, en lo que, nuestras fuerzas y fortuna, nos permitan.

Por lo mismo, y he aquí que hemos vuelto a la cuestión que motivan estas cavilaciones, vivir una existencia auténtica supone el pensar lo que queremos hacer de ella y lo que efectivamente estamos haciendo con ella.

Gabriel Marcel escribió aquello de "Quien no vive como piensa, acaba pensando como vive”. Quien, por el contrario, vive como piensa, tiene por blanco el sentido y la felicidad como camino.

\section{Conflicto de intereses}

El autor declara no tener conflicto de intereses.

\section{Agradecimientos}

Agradezco a la Dra. Pamela Hérnadez su apoyo y reflexiones sin las cuales este artículo no hubiese tenido mayor sentido.

\section{Referencias}

1. Arendt H. La vida del espíritu. Madrid: Centro de Estudios Constitucionales. 1984.

2. Bishop M. Pascal. La Vida de un Genio. México: Editorial Hermes (s.a.).

3. Carr N. ¿Qué está haciendo internet en nuestras mentes? Madrid: Taurus. 2011
4. Carr N. Atrapados. Cómo las máquinas se apoderan de nuestras vidas. Buenos Aires: Taurus. 2015.

5. Han B.Ch. La sociedad del cansancio. Barcelona: Herder. 2012

6. Heidegger M. Ser y tiempo. Santiago de Chile: Editorial Universitaria. 2015.

7. Huizinga J. Homo Ludens. Madrid: Alianza Editorial. 2012.
8. Ortega y Gasset J. En torno a Galileo. Revista de Occidente. Madrid. 1953.

9. Pascal B. Pensamientos. Traducción de Juan Domínguez Berrueta. Buenos Aires: Ediciones Orbis.1q2. 1984.

10. Vargas Llosa M. La civilización del espectáculo. México. D.F.: Editorial Alfaguara. 2012. 